\title{
A Rare Presentation Of Ewing's Sarcoma Involving Spine With Acute Paraplegia
}

\author{
Md. Anowarul Islam ${ }^{1}$, Ahmed Asif Iqbal ${ }^{2}$, Md. Qumruzzaman Parvez ${ }^{3}$, \\ Md.Fahad Goni ${ }^{3}$, Md. Masud Rana ${ }^{3}$, mohd. Alamgir Hossain ${ }^{4}$,
}

\begin{abstract}
Ewing's sarcoma is a primary bone malignancy with the highest incidence in the first decade of life. Although it mostly affects the diaphyseal as well as metaphysical region of growing long bones but involvement of spine is not very uncommon especially the sacrum. Nonsacral spinal Ewing's sarcoma is rarer and often mimics a benign condition before spreading extensively. They present with neurologic deficits due to spinal cord compression, but acute onset paraplegia is very rare.A high index of clinical suspicion can clinch the diagnosis early in the course of the disease. A prompt intervention is required to keep neurological damage to a minimum, and a correct combination of surgery, chemotherapy, and radiotherapy is required for better long-term patient outcome. We report a 15-years old male who presented with acute paraplegia and had an excellent postoperative outcome after posterior decompression of a D 11 Ewing's sarcoma.
\end{abstract}

TAJ 2013; 26: 92-97

\section{Introduction}

Primary malignant sarcomas of the spine are rare and they account for only $3.5 \%-14.9 \%$ of all primary bone sarcomas ${ }^{1}$.Ewing's sarcoma is the second most common primary bone tumor in pediatric patients accounting for approximately $4 \%$ of pediatric malignancies ${ }^{2}$.Its incidence is highest in the first \& second decade of life and most commonly involves the long bones of the extremities and the pelvis, presenting primarily as swelling with pain. Primary vertebral Ewing's sarcoma has been divided into sacral and nonsacral types based on the differences in the treatment responses and survival rates ${ }^{3}$. Primary involvement of the nonsacral spine represents approximately $0.9 \%$ of all cases ${ }^{4}$. Back pain is the most common symptom. Spinal cord compression can produce neurological deficits depending on the tumor location, but is often a delayed presentation. Rapidly progressing paraplegia is uncommon and a high index of suspicion is essential for diagnosis, especially in a young patient. We report a rare case of dorsal spine Ewing's sarcoma that presented with acute onset paraplegia and improved with radical tumor decompression.

\section{Case report:}

A 15-year-old male presented with a 3-weeks history of mild intermittent back pain at the lower thoracic region for which he was treated with analgesics at a local hospital. He presented to us with rapidly deteriorating weakness of both lower limbs within 1 week with loss of bowl and bladder control. There was no antecedent history of

\footnotetext{
${ }^{1}$ Associate Professor, Spine Surgery, Department of Orthopaedic Surgery, Bangabandhu Sheikh Mujib Medical University.

${ }^{2}$ Assistant Professor, Hand \& Micro-Orthopaedic Surgery, Rajshahi Medical College \& Hospital

${ }^{3}$ Resident, Spine Surgery Unit, Bangabandhu Sheikh Mujib Medical University.

${ }^{4}$ Assistant Professor, Department of Orthopadedic Surgery, Rajshahi Medical College \& Hospital
} 
trauma. Constitutional symptoms were present like severe anorexia and weight loss. On examination, there was bilateral spastic paraplegia with only a flicker of movement at the right ankle joint. Sensory examination revealed mild hypoesthesia to all sensations below the level of D11 dermatome. The muscle stretch reflexes of his lower extremities were exaggerated and Babinski response was extensor bilaterally. There was no evidence of any paraspinal tenderness or swelling. Magnetic resonance imaging revealed partial collapse of D11 spine with paraspinal mass formation which extended epidural space and moderately compressed the cord. In view of the rapid progression of weakness, the patient was
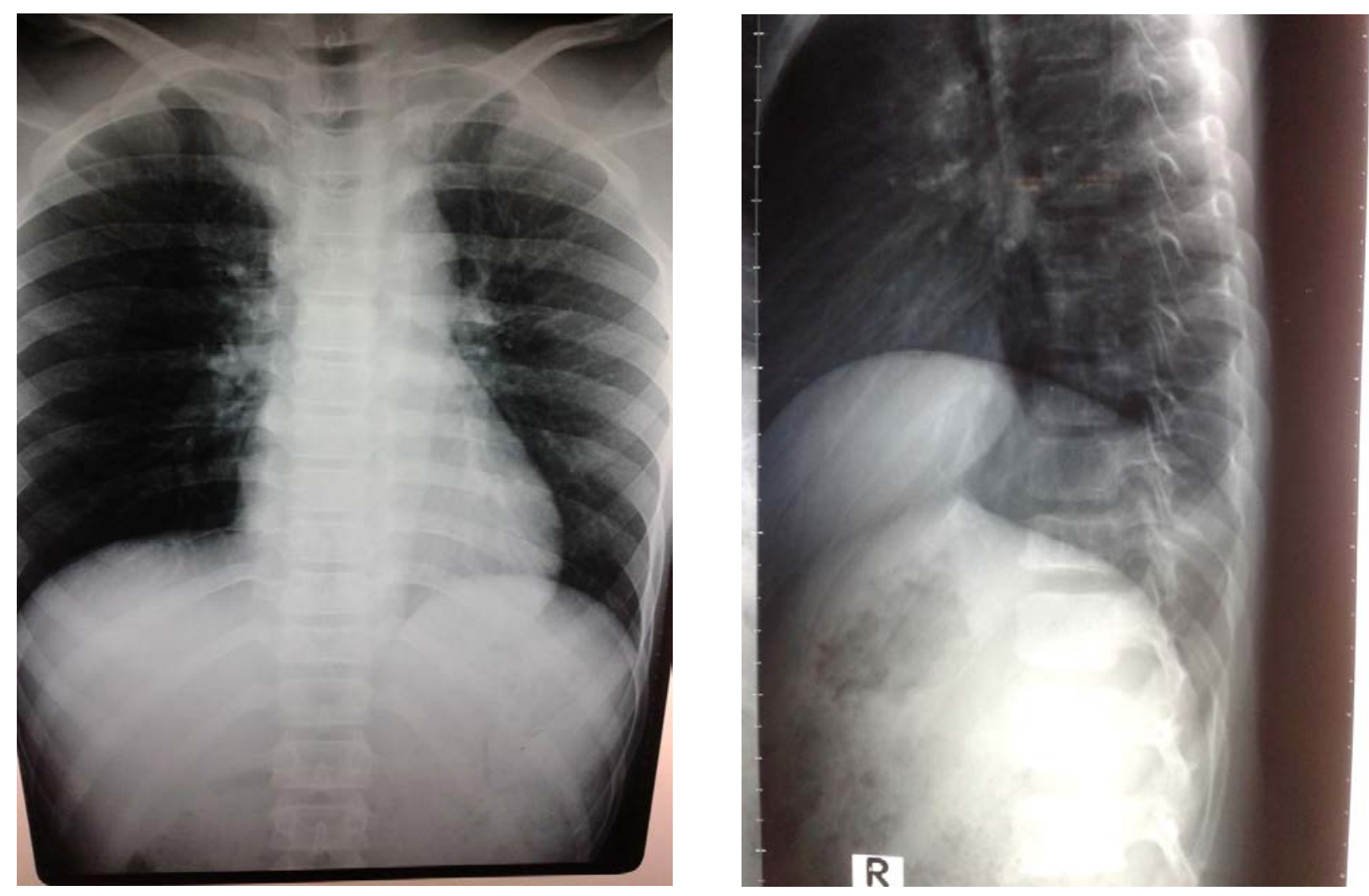

considered for emergency tumor decompression. Intraoperatively, the D11 lamina was eroded by the tumor and there was evidence of minimal paraspinal muscle involvement. The lesion was soft to firm in consistency and highly vascular. The extradural component of the tumor had displaced the cord , but there was no evidence of any dural breach. The tumor was radically excised including the pedicle and part of the body which was involved. He was referred for adjuvant systemic chemotherapy and local radiotherapy. Histopathology report was suggestive of a small round cell tumor possibly Ewing's sarcoma that was confirmed by immunohistochemistry

\section{Preoperative X-Ray}



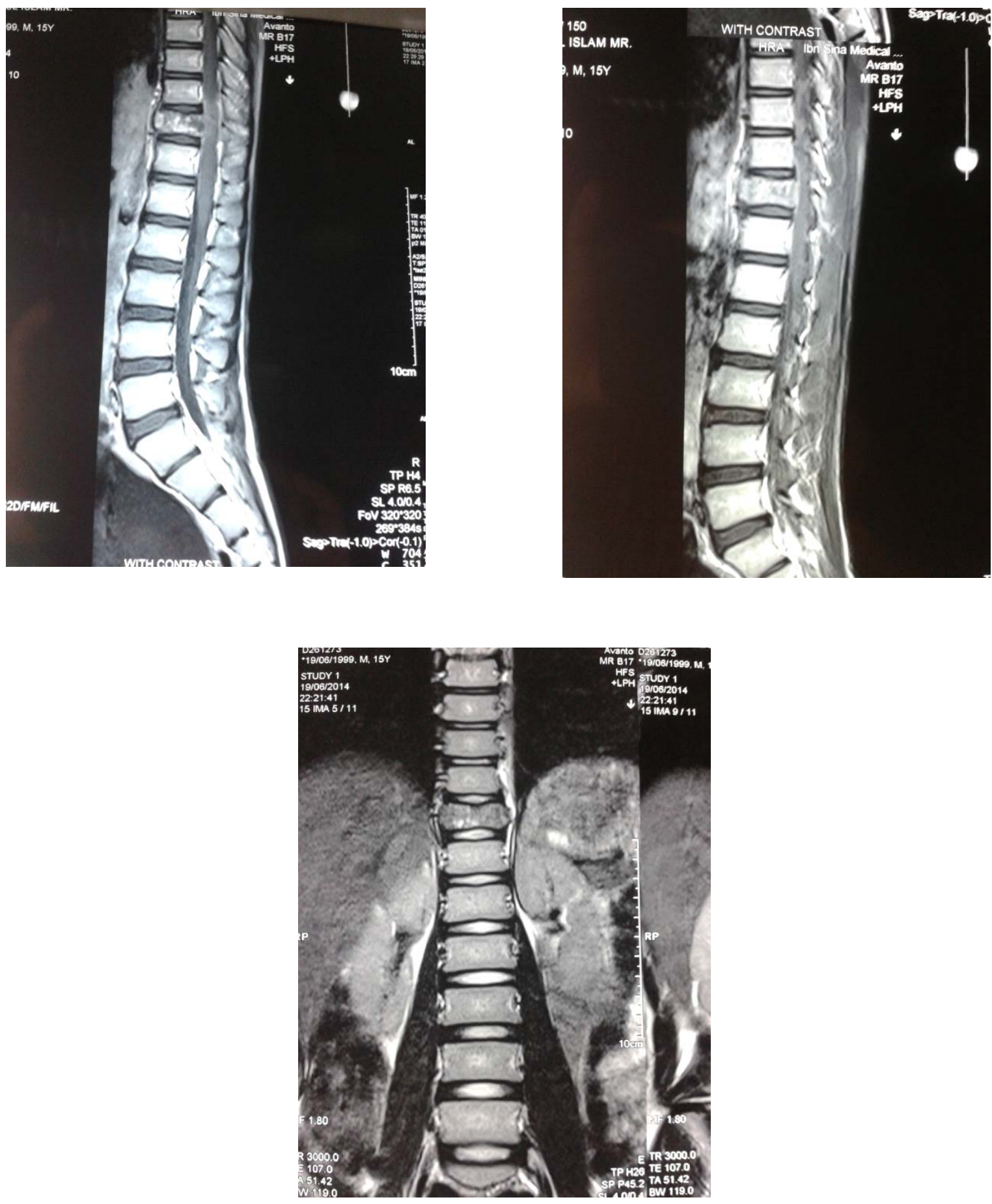

Preoperative MRI Saggital \& Coronal View 


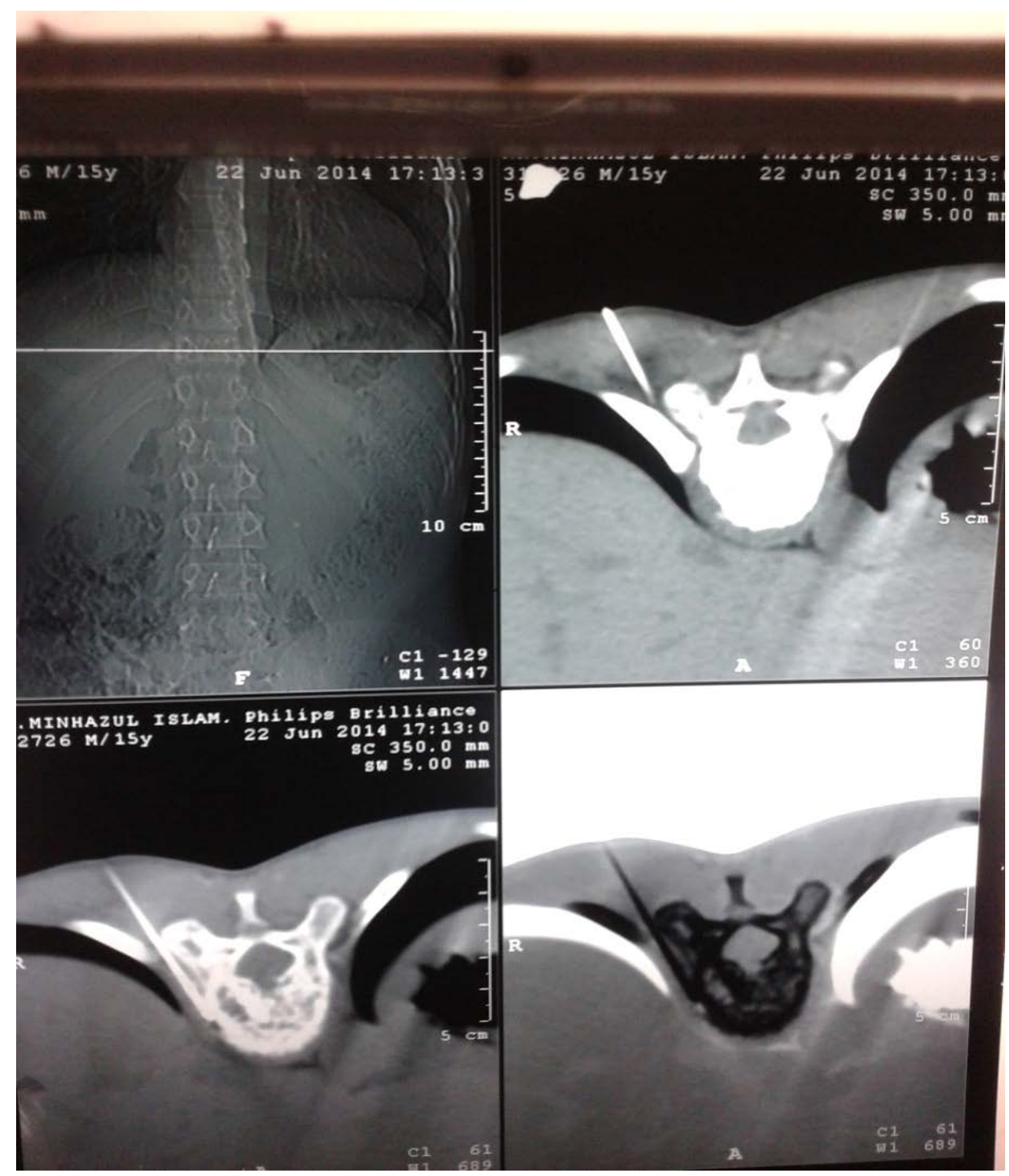

CT Guided FNAC film 

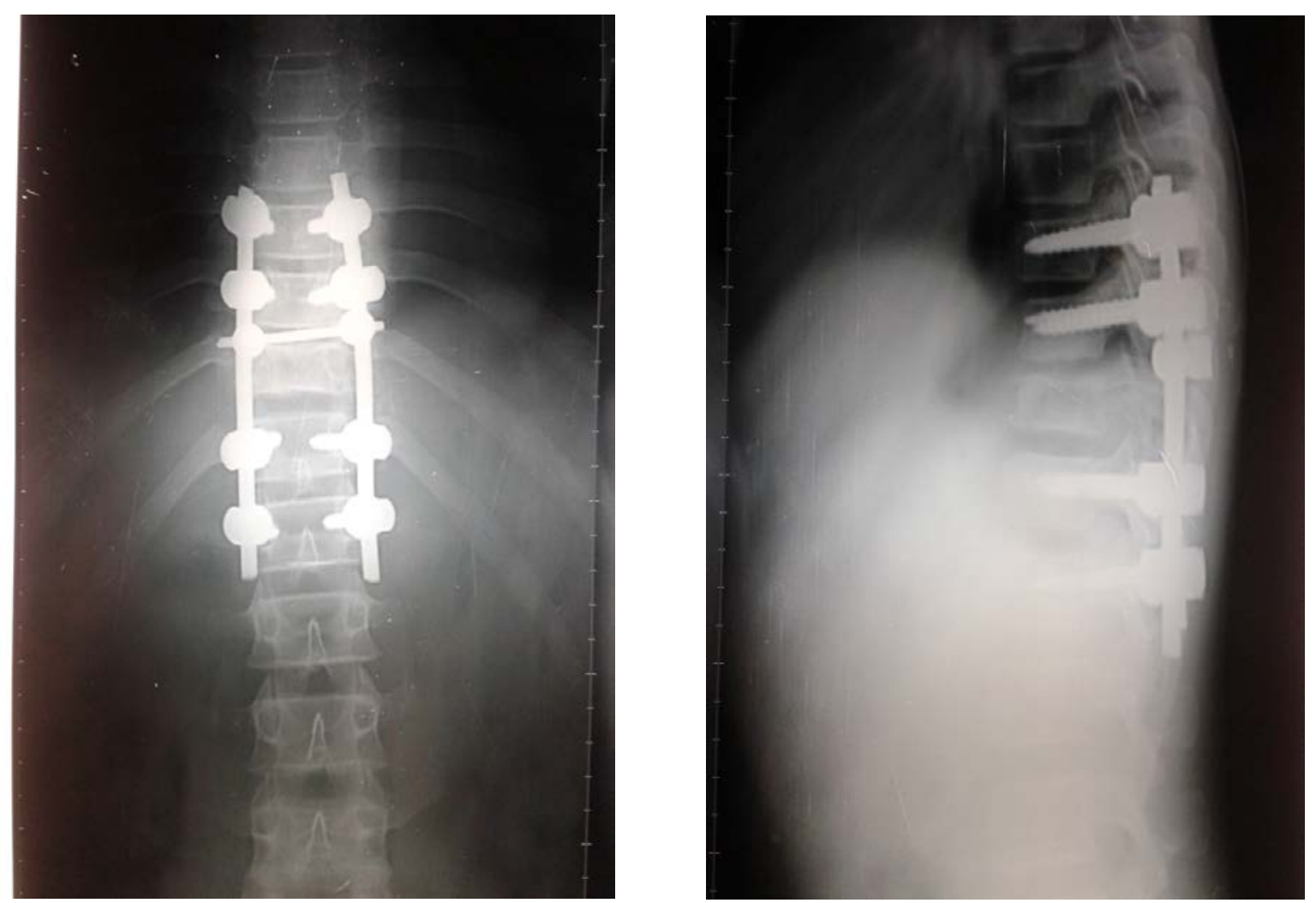

Postoperative X-Ray

\section{Discussion}

The complex neuromusculoskeletal development of the spine may account for a spectrum of malignant tumors with distinct biological behaviors. The differential diagnosis of a small round cell bone tumor includes Ewing's sarcoma, neuroblastoma, primitive, neuroectodermal (PNET) tumor of bone, malignant lymphoma, and rhabdomyosarcoma. Ewing's sarcoma mostly occurs in childhood when the bones are growing. It commonly affects the metaphysiodiaphyseal region of long bones and rarely involves the spine where the most common location is the sacrum. Although there have been reports of nonsacral spinal involvement but these are rare $^{5}$.Ewing's sarcoma is often a multifocal disease, and a proper pre-staging workup including bone scan is required before institution of therapy and for follow-up ${ }^{6}$.The expansile nature of the lesion makes local swelling and pain as the most common presentation in cases of long bone involvement. Early diagnosis and treatment in Ewing's sarcoma can result in favorable outcomes. The presence of benign musculoskeletal symptoms often leads to a delay in diagnosis .Many patients being misdiagnosed and treated for disc disease. Unlike other malignant spinal lesions that cause progressive and continuous pain that increases with recumbency, in majority of nonsacral spinal Ewing's sarcoma pain is often intermittent, without nocturnal exacerbation ${ }^{7}$. This intermittent progression versus an expected rapid course is a reason for further delay in diagnosis. Thus, it is clear that diagnosis of nonsacral spinal Ewing's sarcoma will require a high index of suspicion. A detailed patient history and a careful physical examination supplemented by imaging are essential to minimize the delay. When deciding about the treatment of Ewing's sarcoma of the mobile spine, the most important determinant is 
the presence of neurological deficits, which once present are often rapidly progressive. In such circumstances, only a prompt surgical decompression can provide maximum chance of recovery $^{8}$. In either of the cases, postoperative chemotherapy for control of micrometastases and local control by radiotherapy is warranted. In cases where the diagnosis is being anticipated prior to neurological compromise, it is advisable to confirm it by needle biopsy, and once made, the patient should be subjected to a three- or four-drug neoadjuvant chemotherapy regimen ${ }^{9}$. This would not only help shrink the primary tumor, thereby increasing chances of total excision, but also take care of micrometastasis and give an idea about responsiveness of the tumor to adjuvant therapy ${ }^{10}$.This is followed by surgery or radiotherapy or both. Primary radiotherapy is not advocated in these cases because the post treatment edema will lead to development or progression of neural compression. In our patient, the initial presentation of mild back pain was misinterpreted as due to benign spinal pathology and managed medically.But the onset of rapid lower limb weakness pointed toward a more aggressive pathology.

\section{References}

1. Bacci G, Picci P, Gherlinzoni F, Capanna R, Calderoni P, Putti C, et al. Localized Ewing's sarcoma of bone: Ten years' experience at the Instituto Orthopedico Rizzoli in 124 cases treated with multimodal therapy. Eur J Cancer Clin Oncol. 1985;21:163-73.

2. Ebb DH, Green DM, Shamberger RC, Tarbell NJ. Solid tumours of childhood. In: DeVita VT Jr, Hellman S, Rosenberg SA, editors. Cancer Principles and Practice of Oncology. Philadelphia: Lippincott; 2005. pp. 1919-23.

3. Pilepich MV, Vietti TJ, Nesbit ME, Tefft M, Kissane J, Burgert O, et al. Ewing's sarcoma of the vertebral column. Int J Radiat Oncol Biol Phys. 1981;7:27-31.

4. Bemporad JA, Sze G, Chaloupka JC, Duncan C. Pseudohemangioma of the vertebra: An unusual radiographic manifestation of primary Ewing's sarcoma. AJNR Am J Neuroradiol. 1999;20:180913.

5. Grubb MR, Currier BL, Pritchard DJ, Ebersold MJ. Primary Ewing's sarcoma of the spine. Spine (Phila Pa 1976) 1994;19:309-13.

6. Estes DN, Magill HL, Thompson EI, Hayes FA. Primary Ewing's sarcoma: Follow-up with Ga-67 scintigraphy. Radiology. 1990;177:449-53.

7. Widhe $B$, Widhe $T$. Initial symptoms and clinical features in osteosarcoma and Ewing sarcoma. J Bone Joint Surg Am. 2000;82:667-74.

8. Sharafuddin MJ, Haddad FS, Hitchon PW, Haddad SF, el-Khoury GY. Treatment options in primary Ewing's sarcoma of the spine: Report of seven cases and review of the literature. Neurosurgery. 1992;30:610-8.

9. Bruckner JD, Conrad EU., 3rd . Spine. In: Simon MA, Springfield D, editors. Surgery for bone and soft-tissue tumours. Philadelphia: Lippincott-Raven; 1998. pp. 435-50.

10. Dini LI, Mendonça R, Gallo P. Primary Ewings sarcoma of the spine: Case report. Arq Neuropsiquiatr. 2006;64:654-9. 